\title{
A variant in interleukin-2 gene is associated with repeated spontaneous abortion in Ningxia Han people
}

\author{
Liguo Pei ${ }^{1,2}$, Fan Yang ${ }^{1,2}$, Chuan Zhang ${ }^{1,2}$, Mengjing Guo ${ }^{1,2}$, Junhua Bao ${ }^{3}$, Hong $\mathrm{Lu}^{1,2}$, \\ Zhenghao Huo ${ }^{1,2^{*}}$
}

${ }^{1}$ Key Laboratory of Fertility Preservation and Maintenance, Ministry of Education, Key Laboratory of Reproduction and Heredity of Ningxia Hui Autonomous Region, Yinchuan, China

${ }^{2}$ Department of Medical Genetics and Cell Biology, Ningxia Medical University, Yinchuan, China

${ }^{3}$ Yinchuan Maternal Child Health Care Hospital, Yinchuan, China

Email:

Received 26 April 2013; revised 28 May 2013; accepted 6 June 2013

Copyright (C) 2013 Liguo Pei et al. This is an open access article distributed under the Creative Commons Attribution License, which permits unrestricted use, distribution, and reproduction in any medium, provided the original work is properly cited.

\begin{abstract}
Background: Recurrent spontaneous abortion (RSA) is defined as the occurrence of three or more consecutive spontaneous abortion prior to 20 weeks from the last menstrual period. It affects approximately $1 \%$ to $2 \%$ of women, and about $40 \%-80 \%$ of RSA are still remained unexplained. In recent years, a lot of studies suggest that RSA is caused by the immune factors. $T$ helper 1(Th1)-type immunity is associated with unsuccessful pregnancy especially in women with RSA, while Th2-type immunity is associated with pregnancy success. Interleukin (IL)-2 may influence Th1/Th2 immune responsiveness and has been implicated association with RSA. Aim: The aim of this study was to investigate the association of the interleukin 2 (IL-2) promoter polymorphisms at the site -330 A/C (rs2069762) with RSA. Methods: The study group comprised 189 women with RSA, and the control group consisted of 187 healthy pregnant women. Gene polymorphisms were detected by the technique of polymerase chain reaction restriction fragment length polymorphism. Results: The frequency of genotype $-330 \mathrm{C} / \mathrm{C}$ was significant higher $\left(\chi^{2}=\mathbf{7 . 2 6 6}\right.$, $\mathrm{p}=0.007, \mathrm{OR}=0.362,95 \% \mathrm{CI}=0.169-0.777)$ in the control group than in the patient group. And the frequency of the $-330 \mathrm{~A}$ allele was significant higher $\left(\chi^{2}=\right.$ $11.862, p=0.001, O R=1.741,95 \% \mathrm{CI}=1.268-2.389$ ) in the patient group than in the control group. Conclusions: This study indicated that the IL-2-330A allele may be considered as a risk factor for RSA. C $\rightarrow$ A mutation is may associated with RSA in Ningxia Han people.
\end{abstract}

\footnotetext{
"Corresponding author.
}

Keywords: Repeated Spontaneous Abortion; Interleukin-2; Polymorphism

\section{INTRODUCTION}

Recurrent spontaneous abortion (RSA) is a common disease during early gestation. RSA is defined as the occurrence of three or more consecutive spontaneous abortion prior to 20 weeks from the last menstrual period. It is one of the most common complications of pregnancy and affects approximately $1 \%$ to $2 \%$ of women $[1,2]$. The etiology is complex: chromosomal abnormalities, anatomical abnormalities of factors, endocrine abnormalities, immune factors, blood group incompatibility, smoking and alcohol consumption, infection and even spiritual factors can lead to the occurrence of repeated spontaneous abortion [3]. About $40 \%-60 \%$ of RSA are still remain unexplained. In recent years, a lot of studies suggest that RSA is caused by the immune factors, immune factors in cytokine gene polymorphisms are currently the focus of attention.

Inflammatory cytokines play a critical role in the pathogenesis of unexplained RSA. T helper 1 (Th1)-type immunity is associated with unsuccessful pregnancy especially in women with RSA, while Th2-type immunity is associated with pregnancy success [2-4]. $\mathrm{T}$ cells responses is characterized by the presence of their relative cytokines; (IL-2, IL-12, TNF and IFN- $\gamma$ ) for Th1 cells, whereas a Th2 response is characterized by IL-4, IL-5, IL-6 and IL-10 [5-7]. The imbalance between Th1 and Th2 may be greatly related to the outcome of RSA $[8,9]$. The Th1 cytokine production may be up regulated in women with RSA [10]. And it has been demonstrated that Th1 cytokines are produced at higher concentrations by the women with a history of RSA than by women 
with a history of normal pregnancy in the first trimester [5] and at delivery [11]. Not only Increased T helper 1 cytokine responses by circulating $\mathrm{T}$ cells would cause RSA, but also cause infertile women with multiple implantation failures after in-vitro fertilization (IVF) [12]. Makhseed M., et al., conclude that abortion-prone women who proceed to have successful pregnancy are more Th2-biased than abortion-prone women who abort, and that recurrent aborters who undergo spontaneous abortion have a stronger Th1 bias than aborters who have normal pregnancy [13].

IL-2 is a very important Inflammatory cytokine, Abnormalities of IL-2 production have been found in patients undergoing transplant rejection [14]. A lot of studies have been shown that the higher levels of circulating IL-2 were related to RSA [15-18]. However, contradictory results have also been published [19].

IL-2 production is under genetic control in humans. It has been shown that different genotype at the site $-330 \mathrm{~A} / \mathrm{C}$ (rs2069762) in the promoter region of the IL-2 gene is associated with the production of IL-2 [20]. Therefore, we determined whether this polymorphism is associated with RSA.

\section{MATERIAL AND METHODS}

\subsection{Subjects}

The control group included 187 Ningxia women (mean age $27.44 \pm 3.87$ ) who have previously had at least two normal pregnancies with no history of abortion, ectopic pregnancy, pre-term delivery or stillbirth. The patient group comprised 189 Ningxia women (mean age $26.84 \pm$ 3.51) with a history of at least three consecutive spontaneous abortions. All subjects were fully investigated for possible anatomical, endocrinological, infectious, genetic, autoimmune disease and humoral immune disease that cause of abortion. None of all the subjects with any medication would affect the immune system. No obvious cause for RSA was found in our patient group, thus, the abortions were classified as "unexplained". All subjects were come from the General Hospital of Ningxia Medical University and have diagnosed by professional doctor of obstetrics and gynecology department. There were no significant differences in age between cases and controls (Student's t-test; $\mathrm{p}=0.76$ ). This study was conducted with all the subjects' informed consent and approved by the institutional ethical boards for Genetic studies at Ningxia Medical University.

\subsection{Determination of the -330 IL-2 Polymorphism}

Total genomic DNA from peripheral blood leukocytes was extracted by use the blood DNA isolation kit of Tian Gen company. Sequence amplification was performed by using polymerase chain reaction (PCR). The primers were designed by using Primer 5.0:F:5'-TAT TCA CAT GTT CAG TGT AGT TCT-3', R:5'-CTC TTT GTT ACA TTA GCC CA-3'. PCR was performed in a total volume of $12.5 \mu \mathrm{l}\left(6.25 \mu \mathrm{l} 2 \times\right.$ Reaction Mix, $5.125 \mu \mathrm{ldd} \mathrm{H}_{2} \mathrm{O}$, 0.125 Taq DNA polymerase, $0.25 \mu \mathrm{l}$ of each primer and $0.5 \mu \mathrm{l}$ of genomic DNA). The cycling conditions were as follows: an initial denaturation at $95^{\circ} \mathrm{C}$ for $4 \mathrm{~min}$, followed by 35 cycles at $95^{\circ} \mathrm{C}$ for $30 \mathrm{~s}, 60^{\circ} \mathrm{C}$ for $30 \mathrm{~s}$ and $72^{\circ} \mathrm{C}$ for $40 \mathrm{~s}$, with a final extension step of $7 \mathrm{~min}$ at $72^{\circ} \mathrm{C}$ in the last cycle. The PCR products were visualized under UV light with ethidium bromide stain after 1.5\% agarose gel electrophoresis. The PCR products were incubated at $37^{\circ} \mathrm{C}$ with FspBI (TIANGEN BIOTECH BEIJING CO., LTD.) to detect the IL-2 alleles and then subjected to $3 \%$ agarose gel electrophoresis. Three genotypes were found in our study: genotype A/A, have one fragment, $159 \mathrm{bp}$; genotype $\mathrm{A} / \mathrm{C}$, have three fragments, $159 \mathrm{bp}, 23 \mathrm{bp}$ and $136 \mathrm{bp}$; genotype $\mathrm{C} / \mathrm{C}$, have two fragments, $23 \mathrm{bp}$ and $136 \mathrm{bp}$.

\section{STATISTICAL ANALYSIS}

For statistical analysis, Chi-aquare test was used to compare the allele and genotype frequencies. Means and standard deviations (SD) are presented for describing variables with continuous distribution. The odds ratio (OR) was used to estimate the ratio of the risk of RSA among patient group with various allele or genotype to the risk among control group. The 95\% confidence interval (CI) for OR was calculated using confields' method. All testing for statistical significance was performed at $\mathrm{p}<0.05$.

\section{RESULTS}

Results of polymorphism analysis between patient and control group are given in Table 1. There was a statistically significant association between patient and control group $\left(\chi^{2}=11.851, \mathrm{p}<0.01\right)$. The date suggested that this polymorphism was associated with RSA. Occurred with the allele A of the risk of recurrent miscarriage was significantly increased $\left(\chi^{2}=11.862, \mathrm{p}<0.01, \mathrm{OR}=\right.$ $1.741,95 \% \mathrm{CI}: 1.268-2.389)$.

\section{DISCUSSION}

Our findings demonstrate that women in the RSA group have a significantly greater frequency of Genotype AA than women in the control group.

Study has been shown that pregnancy is associated with a down-regulation of Th1-type activity and enhancement of Th2-type activity [8]. Women with normal pregnancy have a higher Th2-type basis, whereas women with a history of RSA have a basis towards Th1-type reactivity [15]. IL-2 is a very important inflammatory cy- 
Table 1. Allele and genotype frequencies of the $-330 \mathrm{~A} / \mathrm{C}$ polymorphism in the IL-2 gene promoter in women with recurrent spontaneous abortions and in the control group.

\begin{tabular}{ccccccc}
\hline SNP & Genotype & Control $(\mathrm{n}=187)$ & Patient $(\mathrm{n}=189)$ & $\chi^{2}$ & $\mathrm{p}$ & OR (95\%CI) \\
\hline rs2069762 & AA & $79(42.25 \%)$ & $108(57.14 \%)$ & 8.344 & 0.004 & $1.823[1.211-2.744]$ \\
& AC & $83(44.38 \%)$ & $71(37.57 \%)$ & 1.807 & 0.179 & $0.754[0.499-1.138]$ \\
CC & $25(13.37 \%)$ & $10(5.29 \%)$ & 7.266 & 0.007 & $0.362[0.169-0.777]$ \\
& & & 11.851 & 0.003 & \\
Allele & & & & & \\
A & $241(64.44 \%)$ & $287(75.93 \%)$ & 11.862 & 0.001 & $0.574[1.268-2.389]$ \\
& C & $133(35.56 \%)$ & $91(24.07 \%)$ & 11.862 & 0.001 & $0.419-0.789]$ \\
\hline
\end{tabular}

tokine which produced by Th1 cells. It can induce T cells proliferation and differentiation, promote the regulatory $\mathrm{T}$ cells in playing immunosuppression function [13]. In addition, the role of IL-2 also includes enhancing the role of cytotoxic T cells induced by IL-2 receptor expression, promoting cell migration, enhancing the contact between the cells and inducing cytokine secretion. Studies have shown that IL-2 levels of abnormal not only associated with certain $\mathrm{T}$ cell mediated autoimmune diseases [21], but also with some of the endocrine system diseases [22] and tumor [23]. During pregnancy, IL-2 activate T cells to promote secretion of HLA-Class II molecules and a variety of cytokines, and also activate natural killer (NK) cells, which can enhance the secretion of inflammatory factors, make the embryo being rejected [18].

In animal models it has been shown that IL-2 was significantly increased in the CBA/JDBA/2J pregnant mice which have the tendency of abortion. After intraperitoneal injection of IL-2, the abortion rate increased from $25 \%-30 \%$ to $68 \%-79 \%$. Give normal CBA/JDBA/2J mice injected with IL-2, the abortion rate was increased significantly [24]. Another study has showed that the levels of IL-2 mRNA were significantly higher in the patient group than in the control group [18]. Abbas Rezaei's study shows that the levels of IL-2 were significantly higher in the patient group than in the control group [15].

However, contradictory results have also been published. Domestic and foreign research results are inconsistent, some studies have shown comparative the normal population, women with recurrent spontaneous abortion have lower IL-2 levels in vivo [19,25]. IL-2 not only in the clones of $\mathrm{T}$ cells play a key role also involved in the activation of natural killer cells and increased B cell growth and immunoglobulin production [26]. Mallmann $\mathrm{P}$ et al. assumed that Low IL-2 serum levels in women with recurrent miscarriage probably may be associated with a lack of T- and B-cell growth promoting effects which in its turn lead to insufficient induction of a preg- nancy protecting maternal immune response. The possible cause of low IL-2 serum levels could be reduced maternal immunization against paternal antigens [19].

To our knowledge, IL-2 polymorphisms have not been previously characterized in RSA. We became interested in IL-2 as an important inflammatory cytokine at the feto-placental interface. IL-2-330A/C polymorphism is associated with the production of IL-2. It has been shown that the allele $\mathrm{C}$ at the site -330 in the promoter region of the IL-2 gene is associated with high and the allele A with low production [20]. We found there was more AA genotype in the patient group than in the control group, and the difference was significant $\left(\chi^{2}=8.344, \mathrm{p}<0.004\right)$. The samples we sued in this study may be limited by the number of samples, race, geographical differences and others factors, thus, the need for more samples, different regions and ethnic extensive and in-depth collaborative research.

The dates described in this paper suggest that IL-2 $-330 \mathrm{~A} / \mathrm{C}$ polymorphism is associated with RSA. Yet, further more studies need to be done.

\section{ACKNOWLEDGEMENTS}

The authors wish to thank the General Hospital of Ningxia Medical University and Yincuan Maternal Child Health Care Hospital for providing samples for this study. The authors also thank the Key Laboratory of Reproduction and Heredity of Ningxia Hui Autonomous Region for providing the technical assistance.

\section{REFERENCES}

[1] Alberman, E. (1988) The epidemiology of repeated abortion. In: Beard, R.W. and Sharp, F., Eds., Early pregnancy loss: Mechanisms of treatment, Springer-Verlag, London, 9-17. doi:10.1007/978-1-4471-1658-5_2

[2] Clifford, K., Rai, R. and Watson, H., et al. (1994) An informative protocol for the investigation of recurrent miscarriage: Preliminary experience of 500 consecutive cases. Human Reproduction, 9, 1328-1332. 
http://www.ncbi.nlm.nih.gov/pubmed/7962442

[3] Holly, B., Ford, M.D., Danny, J., Schust, M.D., et al. (2009) Recurrent pregnancy loss: Etiology, diagnosis, and therapy. Reviews in Obstetrics and Gynecology, 2, 76-83.

http://www.ncbi.nlm.nih.gov/pmc/articles/PMC2709325/

[4] Vassiliadou, N., Searle, R.F. and Bulmer, J.N. (1999) Elevated expression of activation molecules by decidual lymphocytes in women suffering spontaneous early pregnancy loss. Human Reproduction, 14, 1994-1200. doi:10.1093/humrep/14.5.1194

[5] Reghupathy, R., Makhseed, M., Azizieh, F., et al. (2000) Cytokine production by maternal lymphocytes during normal human pregnancy and in unexplained recurrent spontaneous abortion. Human Reproduction, 15, 713-718. doi:10.1093/humrep/15.3.713

[6] Beer, A.E., Kwak, J.Y.H., Ruize, J.E., et al. (1996) Immunophenotypic profiles of peripheral blood lymphocytes in women with recurrent prefnancy looses and in fertile women with multiple failed in vitro fertilization cycles. American Journal of Reproductive Immunology, 35, 376-382. doi:10.1111/j.1600-0897.1996.tb00497.x

[7] Leung, S.T., Derecka, K., Mann, C.E., et al. (2000) Uterine lymphocyte distribution and interleukin expression during early pregnancy in cows. Journal of Reproduction and Infertility, 119, 25-33. http://www.reproduction-online.org/content/119/1/25.lon g

[8] Raghupathy, R. (1997) Th1-type immunity is incompatible with successful pregnancy. Immunology Today, 18, 478-482. doi:10.1016/S0167-5699(97)01127-4

[9] Kidd, P. (2003) Th1/Th2 balance: The hypothesis, its limitations, and implications for health and disease. $\mathrm{Al}$ ternative Medicine Review, 8, 223-246.

http://www.altmedrev.com/publications/8/3/223.pdf

[10] Peter, M., Emmer, P.M., Nelen, W.L.O.M., et al. (2000) Peripheral natural killer cytotoxicity and CD56 (+) CD16 $(-)$ cellsincrease during early pregnancy in women with a history of recurrent spontaneous abortion. Human Reproduction, 15, 1163-1169. doi:10.1093/humrep/15.5.1163

[11] Makhseed, M., Raghupathy, R., Azizieh, F., et al. (1999) Mitogen-induced cytokine responses of maternal peripheral blood lymphocytes indicate a differential Th-type bias in normal pregnancy and pregnancy failure. American Journal of Reproductive Immunology, 42, 273-281. doi:10.1111/j.1600-0897.1999.tb00101.x

[12] Kwak-Kim, J.Y., Chung-Bang, H.S., Ng, S.C., et al. (2003) Increased T helper 1 cytokine responses by circulating $\mathrm{T}$ cells are present in women with recurrent pregnancy losses and in infertile women with multiple implantation failures after IVF. Human Reproduction, 18, 767-773. doi:10.1093/humrep/deg156

[13] Makhseed, M., Raghupathy, R., Azizieh, F., et al. (2001) Th1 and Th2 cytokine profiles in recurrent aborters with successful pregnancy and with subsequent abortions. Human Reproduction, 16, 2219-2226.

doi:10.1093/humrep/16.10.2219
[14] Oppenheim, J.J. (1986) Interleukins and interferons in inflammation. The Upjohn Company, Kalamazoo.

[15] Rezaei, A. and Dabbagh, A. (2002) T-helper (1) cytokines increase during early pregnancy in women with a history of recurrent spontaneous abortion. Medical Science Monitor, 8, 607-610.

http://www.ncbi.nlm.nih.gov/pubmed/12165750

[16] Taylor, D.D., Bohler, H.C., Gercel-Taylor, C., et al. (2006) Pregnancy-linked suppression of TcR signaling pathways by a circulating factor absent in recurrent spontaneous pregnancy loss (RPL). Molecular Immunology, 43, 1872 1880. doi:10.1016/j.molimm.2005.10.008

[17] Shang, D.K., Zheng, X.Q., Yan, W.H., et al. (2008) The significance of the serum Th1/Th2 cytokine leves in the recurrent spontaneous abortions. Chinese Journal of Birth Health \& Heredity, 16, 25-26.

http://en.cnki.com.cn/Article_en/CJFDTOTAL-ZYYA20 0804011.htm

[18] Fu, W.Q. and Sill, B. (2007) Correlation of T lymphocyte subsets and serum IL-2, IL-10 with spontaneous abortion. Jiangsu Medical Journal, 33, 328-329. http://lib.cqvip.com/qk/93304X/200704/24303960.html

[19] Mallmann, P., Mallmann, R. and Krebs, D. (1991) Determination of tumor necrosis factor alpha and interleukin 2 in women with idiopathic recurrent miscarriage. Archives of Gynecology and Obstetrics, 249, 73-78. doi:10.1007/BF02390365

[20] Hoffmann, S.C., Stanley, E.M., Darrin-Cox, E., et al. (2001) Association of cytokine polymorphic inheritance and in vitro cytokine production in anti-CD3/CD28stimulated peripheral blood lymphocytes. Transplantation, 72, 1444-1450. doi:10.1097/00007890-200110270-00019

[21] Yu, A.L., Zhang, F.X., Yang, C.G., et al. (2000) Relationship between recurrent spontaneous abortion and interleukin. Chinese Journal of Practical Gynecology and Obstetrics, 4, 227-229.

http://www.cnki.com.cn/Article/CJFDTotal-ZGSF200004 $\underline{022 . h t m}$

[22] Berković, M.C., Jokić, M., Marout, J., Radosević, S., et al. (2010) IL-2-330 T/G SNP and serum values-potential new tumor markers in neuroendocrine tumors of the gastrointestinal tract and pancreas (GEP-NETs). Journal of Molecular Medicine, 88, 423-429. doi:10.1007/s00109-009-0581-X

[23] Shen, Y., Liu, Y., Liu, S., Zhang, A., et al. (2012) The association between $-330 \mathrm{~T} / \mathrm{G}$ polymorphism of interleukin 2 gene and bladder cancer. DNA and Cell Biology, 31, 983-987. doi:10.1089/dna.2011.1476

[24] Chaouat, G., Menu, E., Clark, D.A., et al. (1990) Control of fetal survival in CBA $\times$ DBA $/ 2$ mice by lymphokine therapy. Journal of Reproduction \& Fertility, 89, 447-457. doi:10.1530/jrf.0.0890447

[25] Favier, R., Edelman, P., Mary, J.Y., Sadoul, G. and Douay, L. (1990) Presence of elevated serum interleukin-2 levels in pregnant women. The New England Journal of Medicine, 322, 270. doi:10.1056/NEJM199001253220413 
[26] Brunda, M.Y., Tarnowski, D. and Davatelis, V. (1986) Interaction of recombinant interferons with recombinant interleukin-2: Differential effects on natural killer cell ac- tivity and interleukin-2 activated killer ceils. International Journal of Cancer, 37, 787.

doi:10.1002/ijc.2910370522 